\title{
Socioeconomic status and risk of cancer, cerebral stroke, and death due to coronary heart disease and any disease: a longitudinal study in eastern Finland
}

\author{
JUKKA T SALONEN \\ From the North Karelia Project, Research Institute of Public Health, University of Kuopio, Kuopio, Finland
}

SUMmaRY The association of socioeconomic status with the risk of death from ischaemic heart disease and any disease as well as the risk of cerebral stroke and any cancer was studied in 3644 men aged 30-59, based on a random sample from the population of eastern Finland. Age, smoking, blood pressure, and serum cholesterol concentration were allowed for in multiple logistic models. On the basis of these data, not being married, short education, and low income are associated with an excessive risk of death from ischaemic heart disease and any disease. The data also indicated that men who were not married and who lived in urban areas might have an increased risk of cerebral stroke and those with a short education an increased risk of cancer.

According to previous longitudinal studies socioeconomic status is associated with the risk of coronary heart disease in urban middle-aged men. ${ }^{1-3}$ The association between social status and the risk from various cancers has also been studied. . $^{-6}$ Nevertheless, little is known about the mechanisms through which social living conditions influence the risks of disease. It may be hypothesised that preclinical stages of diseases affect indicators of social status such as occupation and income.

The purpose of the present study was to explore the relationships among various socioeconomic indicators and disease risks in a mainly rural population with a high incidence and mortality from cardiovascular diseases and cancer.

\section{Material and methods}

The material of the study is based on a random sample from the population of eastern Finland, an area with high mortality and morbidity from cardiovascular diseases ${ }^{7}$ and fairly high mortality from cancer. ${ }^{8}$ The sampling frame comprised the people living in the two counties of North Karelia and Kuopio, who were between $25-59$ in 1972 and who were born on the 18th and 28th of each month. The analysis reported here is restricted to men aged 30-59 who reported no myocardial infarction, angina pectoris, valvular heart defect, congestive heart failure, cerebral stroke, diabetes mellitus, or cancer in the $\mathbf{1 2}$ months preceding the baseline survey.
The baseline survey was carried out between February and April in 1972. A self-administered questionnaire was completed followed by a field examination at which the questionnaire was checked, additional questions were asked, and physical measurements made. Data on socioeconomic factors were recorded by the questionnaire. The details of the methods and the field examination have been presented elsewhere..$^{9-11}$ The rate of participation in the field survey or the mail survey was $92 \%$ in all men aged 30-59. The men were followed from 30 April 1972 to 31 December 1978 by linking the data available on the national death certificate register and the national hospital discharge register, using the personal identification code. The personal identification code is missing for about $5 \%$ of the hospital admissions, which are thus lost to follow-up.

Socioeconomic status was described in the study by education years, annual gross income of the family, number of episodes of unemployment in the five years preceding the survey, place of residence, and marital status. These indicators of socioeconomic status were dichotomised in this analysis using the following categories. Education less than eight years, unemployed at least once in five years before the baseline study, family income in 1971-2 below $£ 1000$ a year, urban or rural residence, and married or unmarried.

The relative risks of fatal ischaemic heart disease, cerebral stroke, cancer, and death from any disease were estimated by fitting multiple logistic functions, 
where each of the dichotomised socioeconomic indicators one at a time and age, serum cholesterol concentration, diastolic blood pressure, and the daily number of tobacco products were entered as independent continuous variables; the iterative procedure of Walker and Duncan ${ }^{12}$ was applied. The adjusted relative risks and their confidence intervals were then estimated as antilogarithms of the coefficients.

\section{Results}

The number of men available for this analysis was 3644; of these, 130 died from any disease during the seven year follow-up period, 67 of them from acute ischaemic heart disease (ICD 9, 410-412). During the same period 45 men died or were in hospital due to cerebrovascular disease (ICD 9, 430-437) and 65 men died who were in hospital due to cancer (ICD 9, 140-204).

The relative risks for each socioeconomic variable adjusted for age, serum cholesterol, diastolic blood pressure, and daily tobacco consumption are shown in table 1 , together with the $95 \%$ confidence limits.
An unmarried man had an adjusted relative risk compared with a married man of 2.3 from fatal ischaemic heart disease, $2 \cdot 1$ from an episode of cerebrovascular disease, $2 \cdot 2$ from death due to any disease, and a reduced relative risk of 0.8 from cancer. Men with under eight years' education had adjusted relative risks of $\mathbf{2 \cdot 1}$ from fatal ischaemic heart disease, 1.7 from cerebrovascular disease, 2.1 from cancer, and 1.9 from death due to any disease. Men with family incomes below $£ 1000$ a year had an increased adjusted relative risk only for death from any disease. Unemployment during the previous five years did not give any significant increased risks and men with urban residence had a significantly increased risk of 1.8 only for cerebrovascular disease. This last association became stronger when the other socioeconomic factors were included in the multiple logistic model (adjusted RR $=2 \cdot 5$ ).

In table 2 these relative risks are tabulated for the first two years of follow-up and the subsequent five years. This shows that the increased risk of stroke to the unmarried men was effective only during the first two years and similarly the increased risk of death to men of short education was raised only during the first two years.

Table 1 Adjusted relative risks of fatal ischaemic heart disease, cerebral stroke, cancer, and death from any disease associated with various indicators of socioeconomic status in eastern Finnish men aged 30-59 in 1972

\begin{tabular}{|c|c|c|c|c|}
\hline \multirow[b]{2}{*}{ Socioeconomic indicator and category of exposure* } & \multicolumn{4}{|c|}{ Adjusted $\dagger$ relative disease risk with $95 \%$ confidence interval (in parentheses) } \\
\hline & Fatal IHD & Cerebral stroke & Cancer & Death from any disease \\
\hline Marital status & $2 \cdot 3$ & $2 \cdot 1$ & 0.8 & $2 \cdot 2$ \\
\hline $\begin{array}{l}\text { Education } \\
\text { (Under } 8 \text { years) }\end{array}$ & $\begin{array}{l}(1 \cdot 3-4 \cdot 0) \\
2 \cdot 1 \\
(1 \cdot 1-4 \cdot 0)\end{array}$ & $\begin{array}{l}(1 \cdot 1-4 \cdot 2) \\
1 \cdot 7 \\
(1 \cdot 1-4 \cdot 2)\end{array}$ & $\begin{array}{l}(0 \cdot 4-1 \cdot 7) \\
2 \cdot 1 \\
(1 \cdot 1-4 \cdot 0)\end{array}$ & $\begin{array}{l}(1 \cdot 5-3 \cdot 4) \\
1 \cdot 9 \\
(1 \cdot 2-3 \cdot 0)\end{array}$ \\
\hline $\begin{array}{l}\text { Income } \\
\text { (Gross family income } \leq £ 1000 \text { a year) }\end{array}$ & $\begin{array}{l}1 \cdot 7 \\
(1 \cdot 0-2 \cdot 9)\end{array}$ & $\begin{array}{l}1.6 \\
(0.9-3 \cdot 0)\end{array}$ & $\begin{array}{l}0.9 \\
(0.5-1.5)\end{array}$ & $\begin{array}{l}1 \cdot 8 \\
(1 \cdot 2-2 \cdot 6)\end{array}$ \\
\hline $\begin{array}{l}\text { Employment } \\
\text { (Unemployed at least once/5 years) }\end{array}$ & $\begin{array}{l}1 \cdot 3 \\
(0 \cdot 8-2 \cdot 2)\end{array}$ & $\begin{array}{l}0 \cdot 8 \\
(0 \cdot 4-1 \cdot 7)\end{array}$ & $\begin{array}{l}1 \cdot 4 \\
(0 \cdot 8-2 \cdot 3)\end{array}$ & $\begin{array}{l}1.4 \\
(0.9-2 \cdot 0)\end{array}$ \\
\hline $\begin{array}{l}\text { Place of residence } \\
\text { (Urban) }\end{array}$ & $\begin{array}{l}0.7 \\
(0.4-1 \cdot 3)\end{array}$ & $\begin{array}{l}1 \cdot 8 \\
(1 \cdot 0-3 \cdot 3)\end{array}$ & $\begin{array}{l}0.9 \\
(0.5-1.6)\end{array}$ & $\begin{array}{l}0.9 \\
(0.6-1 \cdot 3)\end{array}$ \\
\hline No of events & 67 & 45 & 65 & 130 \\
\hline
\end{tabular}

"Each social indicator dichotomised: 0 , if no exposure; 1 , if "exposed" (defined in parentheses).

tFrom multiple logistic models including age, serum cholesterol concentration, diastolic blood pressure, and daily number of tobacco products in addition to each social indicator in separate models.

Table 2 Adjusted relative risks of fatal ischaemic heart disease, cerebral stroke, cancer, and death from any disease associated with marital status and education during the follow-up year 1-2 and 3-7 in eastern Finnish men aged 50-59 in 1972

\begin{tabular}{|c|c|c|c|c|c|c|c|c|}
\hline \multirow{3}{*}{$\begin{array}{l}\text { Socioeconomic indicator and } \\
\text { the category of exposure* }\end{array}$} & \multicolumn{8}{|c|}{ Adjusted † relative disease risk with $95 \%$ confidence interval (in parentheses) } \\
\hline & \multicolumn{4}{|l|}{ Years 1-2 } & \multicolumn{4}{|l|}{ Years 3-7 } \\
\hline & Fatal IHD & Stroke & Cancer & Death & Fatal IHD & Stroke & Cancer & Death \\
\hline $\begin{array}{l}\text { Marital status } \\
\text { (Not married) } \\
\text { Education } \\
\text { (Under } 8 \text { years) } \\
\text { No of events }\end{array}$ & $\begin{array}{l}1 \cdot 3 \\
(0 \cdot 3-6 \cdot 2) \\
-\ddagger \\
10\end{array}$ & $\begin{array}{l}2 \cdot 1 \\
(1 \cdot 2-14 \cdot 2) \\
2 \cdot 3 \\
(0 \cdot 4-11 \cdot 5) \\
11\end{array}$ & $\begin{array}{l}0 \cdot 6 \\
(0 \cdot 1-4 \cdot 9) \\
1 \cdot 8 \\
(0 \cdot 4-9 \cdot 3) \\
11\end{array}$ & $\begin{array}{l}2 \cdot 8 \\
(1 \cdot 2-6 \cdot 7) \\
5 \cdot 3 \\
(1 \cdot 2-24 \cdot 0) \\
24\end{array}$ & $\begin{array}{l}2 \cdot 5 \\
(1 \cdot 4-4 \cdot 4) \\
1 \cdot 7 \\
(0 \cdot 9-3 \cdot 2) \\
57\end{array}$ & $\begin{array}{l}1 \cdot 5 \\
(0 \cdot 7-3 \cdot 6) \\
1 \cdot 5 \\
(0 \cdot 6-3 \cdot 7) \\
34\end{array}$ & $\begin{array}{l}0 \cdot 8 \\
(0 \cdot 4-1 \cdot 9) \\
2 \cdot 0 \\
(0 \cdot 9-4 \cdot 1) \\
54\end{array}$ & $\begin{array}{l}2 \cdot 0 \\
(1 \cdot 3-3 \cdot 2) \\
1 \cdot 6 \\
(1 \cdot 0-2 \cdot 6) \\
106\end{array}$ \\
\hline
\end{tabular}

"Each social indicator dichotomised: 0 , if no exposure; 1 , if "exposed" (defined in parentheses).

tFrom multiple logistic models including age, serum cholesterol concentration, diastolic blood pressure, and daily number of tobacco products in addition to each social indicator in separate models.

¥Analysis did not converge in 12 iterations. 
Figures 1 and 2 show the increased risk from combinations of the three socioeconomic risk factors unmarried, short education, and low income. If only one of these factors is present the adjusted relative risk of fatal ischaemic heart disease is 1.37 and of death from any disease is 1.65 , which are not statistically significant, but if two social risk factors are present the relative risks are 2.32 and 1.99 and if three factors are present the relative risks are 4.21 and 4.43 compared with men who had none of these factors.

\section{Discussion}

The present analysis shows an association between death due to ischaemic heart disease and unmarried status, short education, and low income, and similarly for death due to any disease. Cerebrovascular disease associates with unmarried status and urban residence; cancer is associated with short education. These observed associations are based on the seven-year follow-up of a randomly drawn population sample. We have reported on the associations of smoking, blood pressure, and serum cholesterol concentration to the risk of myocardial infarction and death in men, ${ }^{13}$ the relation of low physical activity to the risk of myocardial infarction, cerebral stroke, and death in men and women ${ }^{14}$ and lack of association between serum cholesterol and risk of cancer in the same sample (J T Salonen, submitted for publication). According to the present analysis, the association between socioeconomic factors and the risk of ischaemic heart disease and death is not explained by the three major coronary risk factors. Education seems to have some independent impact on the risk of cancer, even after controlling for age and smoking in multivariate models.

The reliability of these results is somewhat reduced by the small number of events as well as the use of clinical diagnoses in their definition, but this does not hold for deaths from any disease. A potential source of bias is the possibility that there are proportionally more people with poor health or preclinical stages of diseases among those who have low income and who are not married, and the direction of causality would be other than hypothesised. It is less likely that this concerns education, place of residence, or employment. In the present data some of the relative risks differed clearly between the first two and subsequent years of follow-up. This concerns most of all stroke, and it remains uncertain whether the observed associations for stroke are true or are artifacts due to a bias. The same goes for the association between education and the risk of death.

If those people with a short education really run an excessive risk of cancer what could be the

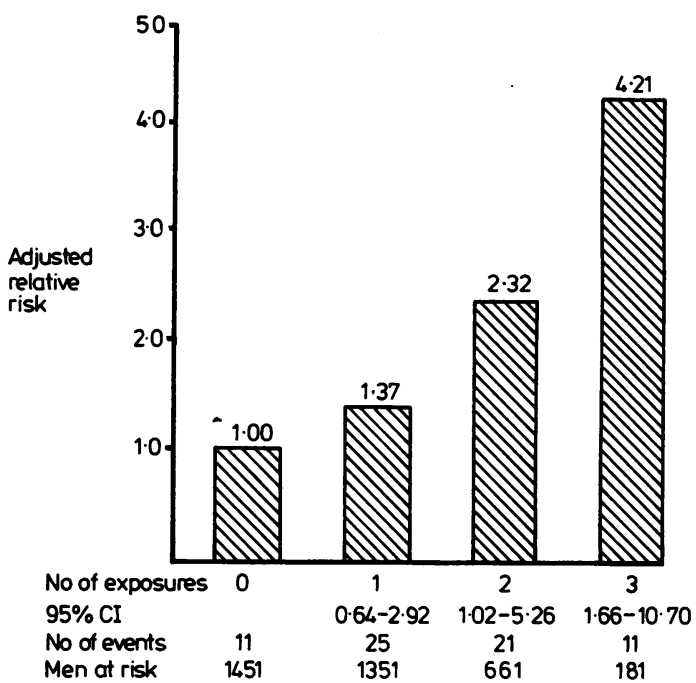

Fig 1 Adjusted relative risk of fatal ischaemic heart disease according to number of exposure categories in marital status, education, and income in Eastern Finnish men aged 30-59 in 1972.

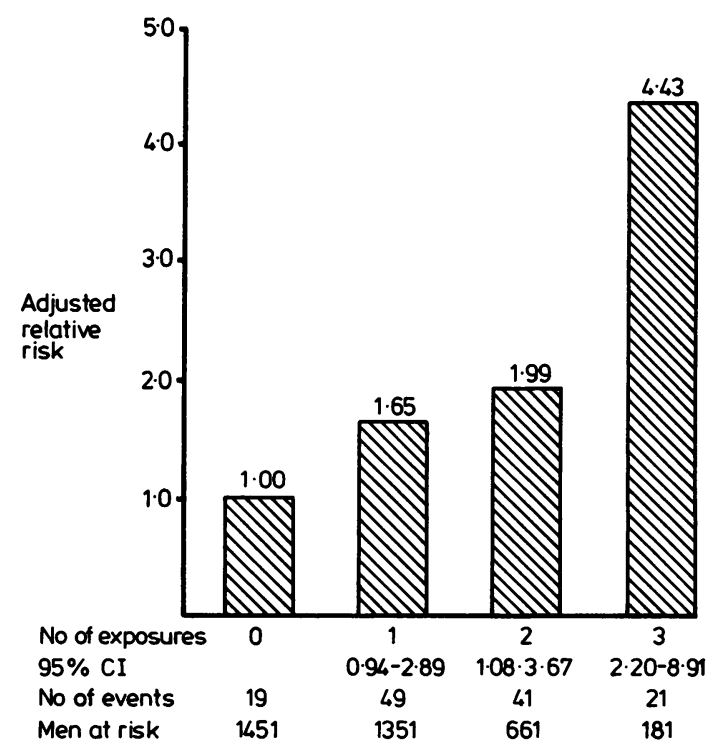

Fig 2 Adjusted relative risk of death from any disease according to number of exposure categories in marital status, education, and income in Eastern Finnish men aged 30-59 in 1972. 
explanation? Differences in diagnosing cancer is unlikely to be the only explanation. According to a Finnish study, people in the lowest socioeconomic group tend to be less active in attending cancer screening services than those with higher socioeconomic status. ${ }^{15}$ It may also be that men with a short education are more often exposed to carcinogenic agents or circumstances in their work. A third possible mechanism would be difference in eating and other habits besides smoking. This finding needs further investigation. A possible approach would be to repeat the analysis in a homogenous occupational group.

The relation of the risk of ischaemic heart disease and death was not abolished by allowing for the major coronary risk factors in the present data. This finding supports the observations of Rose and Marmot $^{1}$ and Holme et al in urban populations. ${ }^{2,3}$ Possible differences between the socioeconomic groups can also exist in physical activity, eating habits, social activity, and personality. A further analysis of the interactions and confounding effects of these factors with the socioeconomic indicators will be carried out in our sample after a longer follow-up period giving a greater number of events. There is still not enough knowledge about the impact of socioeconomic status on the risk of ischaemic heart disease to make any recommendations for primary preventive activities since we do not know the biological pathways lying behind the associations between socioeconomic factors and risk of ischaemic heart disease. Interestingly, urban living was associated in our data with an increased risk of cerebrovascular disease but not that of death from ischaemic heart disease or any disease. A further analysis will be done when the number of strokes allows the break-down by the type of stroke.

\section{References}

${ }^{1}$ Rose G, Marmot MG. Social class and coronary heart disease. Br Heart J 1981; 45: 13-9.
${ }^{2}$ Holme I, Helgeland A, Hjermann I, Leren $\mathbf{P}$, Lund-Larsen PG. Four-year mortality by some socioeconomic indicators: the Oslo study. $J$ Epidemiol Community Health 1980; 34: 48-52.

${ }^{3}$ Holme I, Helgeland A, Hjermann I, Leren $P$, Lund-Larsen PG. Physical activity at work and at leisure in relation to coronary risk factors and social class. Acta Med Scand 1981; 209: 277-83.

${ }^{4}$ Lynch HT, Guirgis H, Lynch J, Brodkey FD, Magee $\mathrm{H}$. Cancer of the colon: socio-economic variables in a community. Am J Epidemiol 1975; 102: 119-27.

${ }^{5}$ Haenszel W, Locke FB, Segi M. A case-control study of large bowel cancer in Japan. Journal of the National Cancer Institute 1980; 64: 17-22.

- Teppo L, Pukkala E, Hakama M, Hakulinen T, Herva A, Saxén E. Way of life and cancer incidence in Finland. A municipality-based ecological analysis. Scand J Soc Med 1980; 19, suppl: 1-84.

${ }^{7}$ Keys A. Coronary heart disease in seven countries. Circulation 1970; 16, suppl: 1.

${ }^{8}$ Teppo L, Hakama M, Hakulinen T, Lehtonen M, Saxén E. Cancer in Finland 1953-1970: incidence, mortality, prevalence. Acta Pathol Microbiol Scand 1975; 252, suppl: $1-79$.

${ }^{9}$ Puska P, Tuomilehto J, et al. The North Karelia project. Evaluation of a comprehensive community programme for control of cardiovascular diseases in North Karelia Finland 1972-1977. Copenhagen: World Health Organisation, Regional Office for Europe, 1981.

${ }^{10}$ Salonen JT. Smoking and dietary fats in relation to estimated risk of myocardial infarction before and during a preventive community programme. Kuopio: University of Kuopio, Community Health, 1980. (Series original reports $1 / 1980$.)

${ }^{11}$ Salonen JT, Puska P, Kottke TE, Tuomilehto J. Changes in smoking, serum cholesterol and blood pressure levels during a community-based cardiovascular disease prevention programme-The North Karelia project. Am J Epidemiol 1981; 114: 81-94.

${ }^{12}$ Walker S, Duncan D. Estimation of the probability of an event as a function of several independent variables. Biometrica 1967; 54: 167-79.

${ }^{13}$ Salonen JT, Puska P, Kottke TE. Smoking, blood pressure and serum cholesterol as risk factors of acute myocardial infarction and death among men in Eastern Finland. Eur Heart $J$ 1981; 2: 365-73.

${ }^{14}$ Salonen JT, Puska P, Tuomilehto J. Physical activity and risk of myocardial infarction, cerebral stroke and death: a longitudinal study in Eastern Finland. Am J Epidemiol 1982; 115: 526-37.

${ }^{15}$ Vuori H, Rimpelä M, Gröhroos M. Gynekologiseen seulontatutkimukseen osallistuminen. Kansanterveystieteen julkaisuja M 7. Turku: Helsingin, Oulun ja Turun yliopistojen kansanterveystieteen laitokset, 1971. 